\title{
Isolated and combined effects of protein and calcium ingestion on postprandial insulinaemia, plasma incretin concentrations, and appetite sensations
}

\author{
J. T. Gonzalez, M. Brown, B. P. Green, P. L. S. Rumbold, L. A. Turner and E. J. Stevenson \\ Nutrition and Exercise Metabolism Research Group, Department for Sport, Exercise and Rehabilitation, \\ Faculty of Health and Life Sciences, Northumbria University, Newcastle-upon-Tyne, NE1 8ST
}

This abstract was presented as the Whole Body Metabolism Theme highlight.

Previous work suggests the calcium content of a meal influences postprandial appetite sensations and insulinaemia ${ }^{(1)}$, which may be explained by elevated incretin hormone concentrations ${ }^{(2)}$. Extracellular calcium and ${ }_{L}$-amino acid concentrations synergistically stimulate secretion of the incretin hormones, glucose-dependent insulinotropic polypeptide (GIP) and glucagon-like peptide- ${ }_{7-36}$ $\left(\mathrm{GLP}_{-1}{ }_{7-36}\right)$, in an isolated rodent intestinal model ${ }^{(3)}$. This synergistic effect of calcium and protein on postprandial incretin hormones has not, to date, been demonstrated in humans. This study aimed to assess the isolated and combined effects of calcium and protein ingestion on postprandial appetite sensations, plasma insulin and incretin hormone concentrations.

Twenty, young, healthy volunteers completed 4 trials in a randomised, double-blind, crossover design. During trials, participants consumed a test meal made from instant oats and water, which was low in protein and calcium $(\mathrm{CON})$, high in protein $(\mathrm{PRO} ; 350 \mathrm{mg} / \mathrm{kg}$ body mass), high in calcium (CAL; $15 \mathrm{mg} / \mathrm{kg}$ body mass) or high in both protein and calcium (PROCAL). Blood samples were collected, at baseline, and 15,30, 45 and $60 \mathrm{~min}$ in the postprandial period to determine plasma concentrations of insulin, GIP and GLP-1 ${ }_{7-36}$. Visual analogue scales were completed to assess subjective appetite sensations, which are expressed as a combined-appetite score (incorporating hunger, fullness, prospective consumption and satisfaction). All data were converted into a time-averaged postprandial area under the curve (AUC). Plasma analysis is ongoing, thus $n=12$ for insulin, and $n=19$ for GLP-1 $1_{7-36}$. GIP data are not yet available.

Repeated measures ANOVA revealed a significant effect of trial on combined-appetite $(P=0 \cdot 024)$ and GLP-1 $1_{7-36}(P<0 \cdot 001)$, but not for insulin concentrations $(P=0 \cdot 116)$. Following adjustment for multiple comparisons, combined-appetite score was lower on PROCAL vs. CON (Table 1), whilst GLP-1 concentrations were higher with PRO and PROCAL vs. CON, and with PRO vs. CAL (Table 1).

Table 1. Postprandial appetite, insulin and GLP-1 ${ }_{7-36}$ responses to the test meals

\begin{tabular}{|c|c|c|c|c|c|c|}
\hline & \multirow{2}{*}{\multicolumn{2}{|c|}{$\begin{array}{l}\text { Combined-appetite } \\
\text { score }(\mathrm{mm})\end{array}$}} & \multicolumn{4}{|c|}{ Time-averaged postprandial area under the curve } \\
\hline & & & \multicolumn{2}{|c|}{$\begin{array}{l}\text { Plasma insulin } \\
\text { concentration }(\mathrm{pmol} / \mathrm{L})\end{array}$} & \multicolumn{2}{|c|}{$\begin{array}{l}\text { Plasma GLP-1 }{ }_{7-36} \\
\text { concentration }(\mathrm{pmol} / \mathrm{L})\end{array}$} \\
\hline & Mean & $\mathrm{SD}$ & Mean & $\overline{\mathrm{SD}}$ & Mean & $\mathrm{SD}$ \\
\hline $\mathrm{CON}$ & 34 & 9 & 207 & 69 & 35 & 31 \\
\hline PRO & 32 & 9 & 256 & 71 & $53 * \#$ & 43 \\
\hline CAL & 30 & 8 & 235 & 87 & 37 & 34 \\
\hline PROCAL & $29 *$ & 9 & 237 & 85 & $47 *$ & 41 \\
\hline
\end{tabular}

These data suggest the intake of protein and calcium in combination, but not alone, significantly suppresses postprandial appetite sensations. Postprandial plasma GLP- $1_{7-36}$ appears to be elevated by protein ingestion independent of calcium, whilst insulinaemia is not significantly affected.

1. Gonzalez JT, Rumbold PLS, Stevenson EJ (2013) Appl Physiol Nutr Metab 38, 1260-1267.

2. Gonzalez JT, Stevenson EJ (2014) Eur J Nutr 53, 375-385.

3. Mace OJ, Schindler M, Patel S (2012) J Physiol 590, 2917-2936. 